Article

\title{
Biofortification of Hens Eggs with Polyunsaturated Fatty Acids by New Dietary Formulation: Supercritical Microalgal Extract
}

\author{
Izabela Michalak ${ }^{1}$, Marita Andrys ${ }^{2}$, Mariusz Korczyński ${ }^{2}$, Sebastian Opaliński ${ }^{2}$, \\ Bogusława Łęska $^{3}$, Damian Konkol ${ }^{2, * \mathbb{D}}$, Radosław Wilk ${ }^{1}$, Edward Rój ${ }^{4}$ (D) and \\ Katarzyna Chojnacka ${ }^{1}$ \\ 1 Department of Advanced Material Technologies, Wrocław University of Science and Technology, \\ Smoluchowskiego 25, 50-372 Wrocław, Poland; izabela.michalak@pwr.edu.pl (I.M.); \\ radekwilk@gmail.com (R.W.); katarzyna.chojnacka@pwr.edu.pl (K.C.) \\ 2 Department of Environment Hygiene and Animal Welfare, Wrocław University of Environmental and Life \\ Sciences, Chełmońskiego 38C, 51-630 Wrocław, Poland; marita.swiniarska@upwr.edu.pl (M.A.); \\ mariusz.korczynski@upwr.edu.pl (M.K.); sebastian.opalinski@upwr.edu.pl (S.O.) \\ 3 Faculty of Chemistry, Adam Mickiewicz University in Poznan, Umultowska 89b, 61-614 Poznań, Poland; \\ bogunial@amu.edu.pl \\ 4 Supercritical Extraction Department, Łukasiewicz Research Network-New Chemical Syntheses Institute, \\ Aleja Tysiąclecia Państwa Polskiego 13a, 24-110 Puławy, Poland; edward.roj@ins.pulawy.pl \\ * Correspondence: damian.konkol@upwr.edu.pl
}

Received: 17 January 2020; Accepted: 15 March 2020; Published: 17 March 2020

check for updates

Simple Summary: Polyunsaturated fatty acids (PUFAs) are essential components of the human diet. The consumption of PUFA can be increased by enriching animal products, such as eggs, with bioactive compounds. New dietary feed supplements were elaborated to increase the level of PUFAs in hens eggs. Nutritional and technological aspects related to the development of functional eggs were discussed. Experimental works dealing with feeding hens new supplements and an investigation of the bioavailability of PUFAs and their transfer to eggs content were undertaken. Analysis of the results obtained during tests showed that used additives may increase the content of such fatty acids (FAs) in eggs: docosapentaenoic acid (DPA, C22:5 n-3), eicosadienoic acid (C22:2 n-6), and the total omega- 6 polyunsaturated fatty acids content (PUFA $n-6)$. The investigated additives may also reduce the content of saturated fatty acids (SFA) such as pentadecanoic acid (C15:0).

Abstract: The aim of the study was to evaluate the effect of Spirulina platensis, formulation containing microalgal extract, post-extraction residue, and formulation without algal extract (containing only emulsifier) on the content of FAs in the eggs of laying hens. The experiment was conducted on 90 laying hens (ISA Brown) as a completely randomized design. Hens were assigned to five experimental groups (six replicates). The FAs content in eggs was determined after 30, 60, 90, and 120 days of the experiment. There were no statistically significant differences in FA profiles after 30 days of the experiment. It was shown that after 60, 90, and 120 days of the experiment, the investigated additives had a significant impact on the content of such acids as: dodecanoic acid (C12:0), C15:0, nonadecanoic acid (C19:0), myristoleic acid (C14:1 n-5), $\alpha$-linolenic acid (ALA, C18:3 n-3), DPA, C20:2 $\mathrm{n}-6$, and decosahexaenoic acid (DHA C22:6 n-6). There were also significant differences in total PUFA $n-3$, PUFA $n-6$, and $n-6 / n-3$ ratio in eggs. The obtained results suggest that the use of algae extract and emulsifier in laying hens nutrition has the greatest impact on the FA profile in the eggs.

Keywords: Functional food; biofortified eggs; dietary feed supplement; supercritical fluid extraction; Spirulina platensis; algae extract 


\section{Introduction}

Recently, a market demand for a new generation of functional food with pro-health benefits has been identified. Consumers have become conscious of the relation of diet to their health. Not only the knowledge about the caloric content of food, but the fact that it provides all the necessary ingredients is now the most important. This created a new niche for products with increased levels of biologically active compounds [1]. An example of such compounds sought after by consumers are PUFAs, mainly due to their health benefits (development and maintenance of brain and vision, protection against cardiovascular diseases) [2].

The market offers many products that are industrially fortified with PUFA n-3 and PUFA n-6 (which differ in the location of the first double bond between the carbon atoms), e.g., oils, mayonnaises, margarines, salad dressings, bakery products, infant formula, milk, meat products, farmed fish, and eggs [3]. Many products fortified with PUFAs origin from poultry production and especially enriched eggs are becoming attractive for the human diet. The poultry diet (chicken/hens) is mainly supplemented with additives rich in PUFAs, for example sardine oil [4], menhaden oil [5], rapeseed/corn oils [6], linseed oil and fish oil [7], flaxseed [8]. However, the main disadvantage of the eggs enriched with FA from, for example, fish oil, is the risk of their oxidation and decrease in PUFA n-3 contents during storage [5].

Other natural source rich in PUFAs, as well as antioxidants are for example marine algae: Sargassum dentifebium [9], Macrocystis pyrifera, Enteromorpha spp., and Sargassum sinicola [4], marine algae (different species) [5] or microalgae [7]: Chlorella spp. [10], Chlorella fusca, Phaeodactylum tricornutum, Isochrysis galbana [11], Schizochytrium sp. [8,12], Nannochloropsis oculata [6], and Nannochloropsis gaditana [13]. It is worth noting that the use of biomass of microalgae (Spirulina maxima) in laying hens diet has already been evaluated by some of the authors of this paper [14].

Usually, poultry diet is based on the standard feeding mixture which is composed of raw materials being rich in PUFAs [15]. In this paper, we propose to use algae in the form of extract added to drinking water. This approach has not been studied so far. Extracts are a concentrated form of biologically active compounds that should be easily bioavailable to animals [16]. For the extraction of active compounds (including PUFAs), we used microalgae Spirulina (Arthrospira) platensis. This alga is produced commercially in large outdoor ponds under controlled conditions or obtained directly from lakes. It is estimated that the current worldwide production of Spirulina is about 3000 metric tons per year. In the last 30 years, it was mainly used for food and specialty feeds [17].

Spirulina sp. serves as a rich source of proteins (higher content than in chicken egg or meat, beef meat, skimmed powdered milk, beer yeast, cheese, fish), vitamins, minerals and pigments [17]. The concentration of lipids in this microalga was examined and it was stated that Spirulina contains 6\%-13\% lipids, half of which can be expressed as total FAs [18]. Zinnai et al. [19] reported that Spirulina platensis is characterised by a lipid fraction with a high proportion of PUFAs such as gamma-linoleic acid (GLA C18:3, n-6). The composition of PUFA in Spirulina sp. depends on many factors, including the environment, growth phase [20], temperature, and composition of a culture medium [21].

Supercritical fluid extraction (SFE) of biologically active compounds from Spirulina sp. was studied. Mendes et al. [22] performed SFE of GLA from Spirulina maxima with $\mathrm{CO}_{2}$ and in the second variant, with addition of a polar co-solvent (ethanol). The addition of ethanol increased the extraction yield of lipids, among others GLA, which was in the glycolipid fraction. Moreover, the extraction yield of GLA also increased with the temperature and pressure. These results were confirmed by Quihui [23], who performed SFE of Spirulina platensis. Andrich et al. [24] extracted oils (mainly GLA) from Spirulina platensis in different experimental conditions (pressure 250,400,550, and 700 bar and temperatures 40 and $55^{\circ} \mathrm{C}, 4 \mathrm{~h}$ ). The highest tested pressure and temperature were the most efficient in the extraction of lipids. It is suggested, in the available literature, that algal extracts can be utilized as a direct source of dietary FAs and may be an alternative to currently available sources of FAs, for manufacturers of products rich in PUFA n-3 and PUFA n-6 [5]. 
Algae biomass is a rich source of FAs. However, it contains fiber that can be a limiting factor in poultry nutrition. Therefore, it is better to use algae extracts. Due to the fact that the extracts have a liquid form, it seems that it is better to use them as supplements for a drinking water which was possible thanks to the investigated formulation. In addition, the extract used as an additive to feed could be exposed to high temperatures during its production, which could have a negative impact on the biologically active compounds contained in it. Emulsifiers are added to increase the solubility of the extracts in water. However, emulsifiers can affect the results of the experiment. The SFE process also produces a large amount of residue, which can also contain biologically active compounds.

Therefore, the aim of the present study was to evaluate the effect of the formulation of SC-extract, microalgae Spirulina platensis, post-extraction residue, and formulation without extract (containing only an emulsifier, as a positive control) on the performance of laying hens, content of FAs in the raw materials, and in the egg yolk.

\section{Materials and Methods}

\subsection{Chemicals}

All used chemicals were of analytical grade.

\subsubsection{Feedstock-Spirulina Lyophilizate}

WB Im-und Export W. Beringer \& Co. GmbH (Görmin, Germany) provided Spirulina platensis which was used in the present study. The composition of the biomass was given by the supplier. It was dark green fine powder with particle size $<80$ mesh. The characteristics of the biomass was as follows: moisture $<8.0 \%$, ash $<10.0 \%$, protein $>60.0 \%$, toxic metals $(\mathrm{Pb}<3.0, \mathrm{Cd}<1.0$, $\left.\mathrm{Hg}<0.1, \mathrm{As}<3.0 \mathrm{mg} \mathrm{kg}^{-1}\right)$. In terms of microbiological composition, the biomass was characterized by: total viable count $<150,000 \mathrm{CFU}$ (Colony Forming Unit) $\mathrm{g}^{-1}$, yeasts and moulds $<100 \mathrm{CFU} \mathrm{g}^{-1}$, Enterobacteriaeae $<100 \mathrm{CFU} \mathrm{g}^{-1}$, Escherichia coli, Staphylococus aureus negative in $1 \mathrm{~g}$, Salmonella negative in $10 \mathrm{~g}$. Spirulina was free from pesticides and preservatives.

\subsubsection{Supercritical Fluid Extraction of the Biomass with $\mathrm{CO}_{2}\left(\mathrm{SFE}-\mathrm{CO}_{2}\right)$}

Microalga Spirulina platensis was subjected to the extraction with carbon dioxide (without addition of co-solvent) at Supercritical Extraction Department in Łukasiewicz Research Network-New Chemical Syntheses Institute in Puławy. The loading capacity of installation was about $1 \mathrm{~L}$. It can operate at pressures up to 1000 bar and extraction temperature up to $200{ }^{\circ} \mathrm{C}$, with a maximum $\mathrm{CO}_{2}$ flow rate up to $15 \mathrm{~L} \cdot \mathrm{h}^{-1}$. Detailed information has been presented by Rój [25]. The experimental conditions were as follows: 700 bar, temperature $40{ }^{\circ} \mathrm{C}$, extraction time $8 \mathrm{~h}$. The extraction yield was $5.6 \%$ from $1 \mathrm{~kg}$ of raw biomass of Spirulina platensis, so $56 \mathrm{~g}$ of the extract was obtained and $903 \mathrm{~g}$ of post-extraction residues. After the extraction process, the extract was stored in tightly closed dark glass bottles to avoid oxidation [26].

\subsubsection{Algal Extract Formulation}

Algal extract from Spirulina platensis obtained by SFE-CO 2 (SC-extract) was used as the component of the formulation designed for feeding experiments on laying hens. The composition of the preparation is presented in Table 1 . The final formulation was easily soluble in drinking water for hens. 
Table 1. The composition of the applied formulation with Spirulina extract (Polish patent application. No P. 412010).

\begin{tabular}{cc}
\hline Component & $\begin{array}{c}\text { The Content of The Components in The } \\
\text { Formulation of SC-Extract (g) }\end{array}$ \\
\hline Spirulina platensis extract (Active ingredient) & 6.70 \\
Bredol 694 (Emulsifier) & 25.0 \\
Potassium sorbate (Preservative) & 0.250 \\
Citric acid (Antioxidant) & 0.500 \\
Water (Solvent) & 468 \\
\hline
\end{tabular}

\subsubsection{Animal Diets and Experimental Design}

The feeding experiments on laying hens were approved by the Second Local Ethical Committee on Animal Testing at Wrocław University of Environmental and Life Sciences (No 5/2015, 21 January 2015). The trials were performed at the research station of Wrocław University of Environmental and Life Sciences in Swojec (Poland).

A total of 90 laying hens (ISA Brown, 36 weeks of age) were housed in a 3-tier battery system, in a room with a controlled climate and light regimen of 16L:8D. The initial laying index, before the beginning of experiment, was on the level of $91 \%$. The feeding experiment was conducted for 120 days. The basal diet (Table 2) was formulated according to the nutrient recommendations for laying hens [27]. The laying hens were fed ad libitum and water was provided by nipple drinkers (volume of $1 \mathrm{~L}$ ) separately for each cage.

Table 2. Ingredients and chemical composition of basal diet [28].

\begin{tabular}{cc}
\hline Feed Material & Diet (88.4\% Dry Matter) $\%$ \\
\hline Wheat & 46.2 \\
Sunflower meal 35\% of total protein (TP) & 5.0 \\
Triticale 11\% TP & 20.0 \\
Soybean oil & 1.4 \\
Soybean meal 46\% TP & 14.0 \\
Beans & 3.0 \\
Monocalcium phosphate & 0.4 \\
Calcium carbonate 38\% & 9.0 \\
PREMIX-POLF KOMPL DJ-1 KOL 1\% * & 1.0 \\
\hline Composition & Percentage (\%) \\
\hline Total protein & 16.9 \\
Crude fat & 2.7 \\
Crude fiber & 3.5 \\
Ash & 12.0 \\
Lysine & 0.77 \\
Methonine + cystine & 0.73 \\
Methionine & 0.42 \\
Threonine & 0.57 \\
Sodium (Na) & 0.17 \\
Calcium (Ca) & 3.65 \\
Phosphorus (P) & 0.32
\end{tabular}

\footnotetext{
* Composition of premix (content per $1 \mathrm{~kg}$ )—vitamins (A (E672 retinol)—1,200,000 IU; $\mathrm{D}_{3}$ (E671 cholecalciferol)— 250,000 IU; E (3a700 octan all-rac-alfa-tokoferyl) - 2500 IU), trace elements $\left(\mathrm{Cu}\left(\mathrm{CuSO}_{4} \cdot 5 \mathrm{H}_{2} \mathrm{O}\right)-1500 \mathrm{mg}\right.$; $\mathrm{Fe}\left(\mathrm{FeSO}_{4} \cdot \mathrm{H}_{2} \mathrm{O}\right)-7000 \mathrm{mg} ; \mathrm{J}(\mathrm{KI})-150 \mathrm{mg} ; \mathrm{Mn}\left(\mathrm{MnO}_{2}\right)-10,000 \mathrm{mg} ; \mathrm{Zn}(\mathrm{ZnO})-8000 \mathrm{mg} ; \mathrm{Se}\left(\mathrm{Na}_{2} \mathrm{SeO}_{4}\right)-20$ $\mathrm{mg}$ ), digestibility enhancers (3-phytaze (E1600)—5000 FTU g ${ }^{-1}$ ), antioxidants (Ethoxyquin (E324)—8 mg; Butylatedhydroxytoluene (BHT) - 55 mg; Butylatedhydroxyanisole (BHA) - 5 mg), dyes (Canthaxanthin (E161g) - $350 \mathrm{mg}$, Ethyl ester of beta-apo-8'-carotenic acid (E160f)—250 mg), aromats—mix-200 mg.
}

The completely randomized design was applied to the feeding experiment. Birds were divided into 5 groups (6 replicates per group, 3 hens in each replicate). The cages were located on the right 
and left side of the battery system. Each replication consisted of cages from the first, second and third floor on the right and left side of the battery system. This layout best reflects conditions in the room. The division of groups was as follows: (1) Control—fed with basal diet and drinking water, (2) Formulation of SC-extract-fed with basal diet and $0.2 \%$ microalgal extract in drinking water; (3) Microalgae — fed with basal diet containing $15 \mathrm{~g} \mathrm{~kg}^{-1}$ of microalgae Spirulina platensis and drinking water; (4) Residue - fed with basal diet containing $15 \mathrm{~g} \mathrm{~kg}^{-1}$ of post-extraction residues and drinking water; (5) Formulation without extract (containing only an emulsifier-positive control) fed with basal diet, and $0.2 \%$ formulation without extract in drinking water. When choosing the doses of extracts that were investigated during the study, the economic criterion was mainly taken into account, i.e., whether the cost of producing the additive (costs of obtaining the raw material, its extraction, and formulation production) would be rational for farmers.

\subsubsection{Performance of Laying Hens}

Throughout the experiment, all groups were monitored for egg production. Eggs were collected and weighed daily. Eggs production was determined by dividing the number of eggs laid over the course of the experiment by the number of hens in the same period (expressed as percentage of egg production). Feed intake was recorded once per week. Feed conversion ratio (FCR) was calculated by dividing the feed intake by the mass of eggs.

\subsection{Sample Collection and Storage of Eggs}

Six randomly collected eggs from each replicate after 30, 60, 90, and 120 days of the experiment in all the examined groups were analyzed. Eggs were broken in order to separate albumen, yolk and shell. Egg yolks from each replicate $(n=6)$ were mixed homogeneously in order to obtain representative samples. Then, samples were kept in the temperature of $-40^{\circ} \mathrm{C}$. In the next step, the samples underwent lyophilization using Free Zone 18 Liter Console Freeze Dry System (Labconco Corporation, Kansas City, MO, USA).

\subsection{Preparation of Samples for FAs Analysis}

\subsubsection{Lyophilized Eggs}

Extraction of lipids from lyophilized eggs $(50 \mathrm{mg})$ was performed according to the Folch method using $10 \mathrm{~mL}$ of the mixture chloroform:methanol $\left(2: 1 ; v v^{-1}\right)$. Extraction was performed by $30 \mathrm{~min}$ providing intensive mixing. Then the solvent from the collected solution $(2 \mathrm{~mL})$ was evaporated in a rotary evaporator at a temperature $<50{ }^{\circ} \mathrm{C}$ until constant weight. In the next step, $0.5 \mathrm{~mL}$ of tert-butyl methyl ether (MTBE) was added to the dry residue. Subsequently, to the mixture of $0.25 \mathrm{~mL}$ of $0.25 \mathrm{M}$ solution of trimethylsulfonium hydroxide in methanol as a derivatizing agent was added. Then, the mixture was stirred for $5 \mathrm{~min}$ in a room temperature. Finally, the internal standard (solution of $10 \mu \mathrm{L}$ of methyl undecanoate, $85 \mathrm{mg}$ in $5 \mathrm{~mL} \mathrm{MTBE)}$ was added.

\subsubsection{Formulation of SC-Extract}

The samples $(0.5 \mathrm{~mL}, n=2)$ of the extract were evaporated in a rotary evaporator at a temperature $<50{ }^{\circ} \mathrm{C}$ until constant weight. We dried the solid residue under vacuum per 10 min which was then dissolved in $0.5 \mathrm{~mL}$ of MTBE. In the next step, $0.25 \mathrm{~mL}$ of $0.25 \mathrm{M}$ solution of trimethylsulfonium hydroxide in methanol was added and after $5 \mathrm{~min}$ of mixing at room temperature, the internal standard (20 $\mu \mathrm{L}$ of methyl undecanoate- $-85 \mathrm{mg}$ in $5 \mathrm{~mL} \mathrm{MTBE}$ ).

\subsubsection{Formulation Without SC-Extract}

Bredol 694 (Emulsifier) (approximately $25 \mathrm{mg}, n=2$ ) was dissolved in $0.5 \mathrm{~mL}$ of MTBE. Then, the procedure was the same as for the formulation of SC-extract. 


\subsubsection{Microalga-Spirulina Platensis and Post-Extraction Residue}

The samples ( $250 \mathrm{mg}, n=2)$ were extracted with $2 \mathrm{~mL}$ of MTBE in the temperature of $70{ }^{\circ} \mathrm{C}$ for $2 \mathrm{~h}$. Then, after cooling the sample, the internal standard $(20 \mu \mathrm{L}$ of methyl undecanoate- $-85 \mathrm{mg}$ in $5 \mathrm{~mL}$ MTBE) was added and the obtained solution was filtered. To $0.5 \mathrm{~mL}$ of the solution derivatizing agent, $0.25 \mathrm{~mL}$ of $0.25 \mathrm{M}$ solution of trimethylsulfonium hydroxide in methanol was added.

\subsection{Fatty Acids Analysis in Samples}

A Varian 450-GC gas chromatograph was used to determine fatty acids as methyl esters. The chromatograph operated on the following parameters: split: 1:50; injector temperature: $250{ }^{\circ} \mathrm{C}$; carrier gas: helium, flow rate $1 \mathrm{~mL} \mathrm{~min}^{-1}$; Agilent HP-INNOWax GC column, $30 \mathrm{~m} \times 0.53 \mathrm{~mm}, 1.0 \mu \mathrm{m}$ film thickness; temperature program: $50{ }^{\circ} \mathrm{C}$ isothermal for $2 \mathrm{~min}$; linear gradient of $10{ }^{\circ} \mathrm{C} \mathrm{min}^{-1}$ to $250{ }^{\circ} \mathrm{C}$ (20 min), isothermal $240{ }^{\circ} \mathrm{C}$ for $22 \mathrm{~min}$; detector: a flame ionization detector (FID), $250{ }^{\circ} \mathrm{C}$. To the injection port, $1 \mu \mathrm{L}$ of the prepared sample was introduced. The retention times of standards was used to identify methyl esters of FAs.

\subsection{Statistical Methods}

The software Statistica ver. 10 was used for the statistical elaboration of the obtained results. Shapiro-Wilk test was applied to assess the normality of the distribution of experimental results and to select an appropriate statistical test in order to investigate the statistically significant differences between the tested groups. In the case of normal distribution, a one-way analysis of variance (ANOVA) with Tukey test was used to investigate the differences between groups. The Kruskal-Wallis test was applied, if the distribution was not normal. Effects were considered significant at a probability of $p<0.05$ and $p<0.01$.

\section{Results and Discussion}

\subsection{Content of FAs in The Raw Materials}

The FAs can be mainly extracted from algal biomass using Soxhlet apparatus with organic solvent or SFE- $\mathrm{CO}_{2}$ as a solvent [29-31]. It was noticed that SFE favored isolation of saturated and unsaturated fatty acids when compared to traditional extraction techniques with the use of organic solvents. Many studies showed that SFE is characterized by a higher efficiency of extraction of biologically active substances from a natural source when compared to other extraction techniques [31,32]. Table 3 presents the percentage weight of FA in dry matter of the samples that were used in laying hens feeding, i.e., microalga Spirulina platensis, formulation of SC-extract from S. platensis, post-extraction residue of S. platensis, and the formulation that was used to prepare the application form of supercritical extract.

The formulation of SC-extract was the main source of FAs, especially 16:0, 16:1 (n-7), 18:0, 18:1 (n-9), 18:2 (n-6) and 18:3 (n-6) when compared with other examined samples (microalgae, residue, formulation without SC-extract). 16:0 was the major FA. These observations are in agreement with the data reported by Andrich et al. [24]. In the SC-extract from S. platensis, the dominating FAs were 16:0 (40\% of total FA by weight at 700 bar, $\left.55^{\circ} \mathrm{C}\right)>18: 3(n-6 ; 20.2 \%)>18: 2(n-6 ; 15.0 \%)>18: 1(n-9 ; 9.9 \%)$. These values were much higher than in the present study, however, we examined the formulation of SC-extract in which the SC-extract constituted $1.34 \%$, not the raw extract.

In the present work, the main FAs, in the biomass of $S$. platensis before extraction process were 16:0 $>18: 2(n-6)>18: 3(n-6)>18: 1(n-9)>16: 1(n-7)=18: 0$. Similar FA present in the Spirulina maxima were reported by Batista et al. [33]: 16:0 (1078 mg 100g $\left.\mathrm{g}^{-1}\right)>18: 2\left(\mathrm{n}-6 ; 481 \mathrm{mg} 100 \mathrm{~g}^{-1}\right)>18: 3$ (n-6;

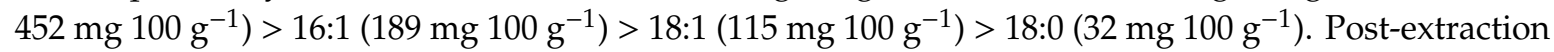
residue and the formulation without SC-extract contained low levels of FAs. On the basis of the preliminary analysis it was supposed that the formulation of SC-extract will be the main source of FAs accumulated in the eggs of laying hens. It is worth noting that relatively large amounts of the 16:0 and palmitoleic acid 16:1 were found in the SC-extract. These FAs, with strong anti-free radical and 
antioxidative properties, rarely occur in algae [34]. In SC-extracts, they become a valuable additive to animal feed.

Table 3. Percentage weight of FAs in the samples used in laying hens feeding.

\begin{tabular}{|c|c|c|c|c|c|c|c|c|}
\hline \multirow{3}{*}{ Fatty Acids } & \multicolumn{8}{|c|}{$\%$ Weight of Fats in Dry Matter of the Samples $(n=2)$} \\
\hline & \multicolumn{2}{|c|}{$\begin{array}{c}\text { Microalga- } \\
\text { Spirulina Platensis }\end{array}$} & \multicolumn{2}{|c|}{$\begin{array}{l}\text { Formulation of } \\
\text { SC-Extract }\end{array}$} & \multicolumn{2}{|c|}{ Residue } & \multicolumn{2}{|c|}{$\begin{array}{c}\text { Formulation without } \\
\text { SC-Extract }\end{array}$} \\
\hline & Mean & SD & Mean & SD & Mean & SD & Mean & SD \\
\hline $6: 00$ & $<0.002$ & - & 0.010 & 0.000 & $<0.002$ & - & n.d. & - \\
\hline $10: 0$ & n.d. & - & $<0.002$ & - & n.d. & - & n.d. & - \\
\hline $12: 0$ & n.d. & - & n.d. & - & n.d. & - & $<0.003$ & - \\
\hline $13: 0$ & n.d. & - & n.d. & - & n.d. & - & $<0.003$ & - \\
\hline $14: 0$ & n.d. & - & 0.020 & 0.000 & n.d. & - & $<0.001$ & - \\
\hline $15: 0$ & n.d. & - & 0.010 & 0.000 & n.d. & - & n.d. & - \\
\hline $16: 0$ & 0.255 & 0.0353 & 1.95 & 0.16 & 0.060 & 0.014 & 0.025 & 0.007 \\
\hline $16: 1(\mathrm{n}-7)$ & 0.020 & 0.000 & 0.200 & 0.028 & 0.010 & 0.000 & n.d. & - \\
\hline $17: 0$ & $<0.002$ & - & 0.020 & 0.000 & n.d. & - & n.d. & - \\
\hline $18: 0$ & 0.020 & 0.000 & 0.305 & 0.021 & 0.010 & 0.000 & 0.010 & 0.000 \\
\hline $18: 1(n-9)$ & 0.040 & 0.000 & 1.12 & 0.07 & 0.015 & 0.007 & 0.030 & 0.000 \\
\hline $18: 2(n-6)$ & 0.155 & 0.007 & 0.925 & 0.063 & 0.035 & 0.021 & n.d. & - \\
\hline $18: 3(n-6)$ & 0.065 & 0.007 & 0.755 & 0.078 & 0.020 & 0.000 & n.d. & - \\
\hline $18: 3(n-3)$ & n.d. & - & $<0.005$ & - & n.d. & - & n.d. & - \\
\hline 19:0 & n.d. & - & n.d. & - & n.d. & - & n.d. & - \\
\hline $20: 1(n-9)$ & n.d. & - & n.d. & - & n.d. & - & n.d. & - \\
\hline $20: 2(n-6)$ & n.d. & - & 0.010 & 0.000 & n.d. & - & n.d. & - \\
\hline $20: 3(n-3)$ & n.d. & - & 0.015 & 0.007 & n.d. & - & n.d. & - \\
\hline $20: 4(n-6)$ & n.d. & - & n.d. & - & n.d. & - & n.d. & - \\
\hline $20: 5(n-3)$ & n.d. & - & 0.080 & 0.014 & n.d. & - & n.d. & - \\
\hline $22: 5(n-3)$ & n.d. & - & n.d. & - & n.d. & - & n.d. & - \\
\hline $22: 6(n-3)$ & n.d. & - & n.d. & - & n.d. & - & n.d. & - \\
\hline
\end{tabular}

Abbreviations: n.d.-not detected; 12:0—lauric acid; 14:0—myristic acid; 14:1 (n-5)—myristoleic acid; 15:0—pentadecylic acid; 16:0—palmitic acid; 16:1 (n-7)—palmitoleic acid; 17:0—margaric acid; 18:0—stearic acid; 18:1 (n-9)—oleic acid; 18:2 (n-6) —linoleic acid; 18:3 (n-6)—gamma-linolenic acid (GLA); 18:3 (n-3)—alpha-linolenic acid (ALA); 19:0—nonadecylic acid; 20:1 (n-9)—eicosenoic acid; 20:2 (n-6)—eicosadienoic acid; 20:3 (n-3)—eicosatrienoic acid (ETE); 20:4 (n-6) -arachidonic acid (AA); $20: 5$ (n-3) eicosapentaenoic acid (EPA); 22:5 (n-3)—docosapentaenoic acid (DPA); 22:6 (n-3) decosahexaenoic acid (DHA).

\subsection{Production Parameters of Laying Hens}

Results on the production parameters of the tested animals are shown in Table 4.

The obtained results did not show any significant positive influence of the investigated additives on the laying rate. However, birds receiving the formulation of SC-extract were characterized by the highest egg production after the 30th, 60th and 90th days of the experiment. Based on the obtained results, it can be concluded that the FCR of hens receiving microalgae was significantly $(p<0.05)$ lower when compared to hens receiving formulation without SC-extract. The FCR of hens receiving microalgae was also the lowest compared to other experimental groups, however, this was not a statistically significant result. Based on the results, it can be concluded that the used additives had no significant effect on laying hen performance. Other results were obtained by Mariey et al. [35], who found that the enrichment of the hens' diet with Spirulina platensis significantly improved egg production and FCR. Zahroojian et al. [36] failed to demonstrate that the use of Spirulina platensis significantly affected egg production, feed intake, and FCR. Other studies of Zahroojian et al. [37] also did not show a significant effect of the use of Spirulina platensis in the diet of laying hens on the performance of birds. 
Table 4. Production parameters of laying hens during the experiment.

\begin{tabular}{|c|c|c|c|c|c|c|c|c|}
\hline Production & Parameters & Control & $\begin{array}{l}\text { Formulation } \\
\text { of SC-Extract }\end{array}$ & $\begin{array}{c}\text { Microalga- } \\
\text { Spirulina } \\
\text { Platensis }\end{array}$ & Residue & $\begin{array}{c}\text { Formulation } \\
\text { without } \\
\text { SC-Extract }\end{array}$ & SEM & $p$-Value \\
\hline \multirow{2}{*}{$\begin{array}{l}\text { Laying index } \\
\qquad(\%)\end{array}$} & After 60 days & 89 & 94 & 93 & 92 & 90 & 1.02 & 0.494 \\
\hline & After 90 days & 87 & 95 & 91 & 90 & 90 & 1.00 & 0.205 \\
\hline \multirow{2}{*}{$\begin{array}{c}\text { FCR (g } \\
\text { feed/g egg) }\end{array}$} & After 30 days & $1.6^{\mathrm{ab}}$ & $1.6^{\mathrm{ab}}$ & $1.2^{\mathrm{a}}$ & $1.7^{\mathrm{ab}}$ & $2.2^{b}$ & 0.09 & 0.022 \\
\hline & After 90 days & $2.0^{\mathrm{ab}}$ & $1.9^{\mathrm{a}}$ & $2.0^{\mathrm{ab}}$ & $2.5^{\mathrm{ab}}$ & $2.7^{\mathrm{b}}$ & 0.09 & 0.027 \\
\hline
\end{tabular}

SEM—standard error of measurements; ${ }^{a}, \mathrm{~b}$ — statistically significant differences between the groups for individual parameters, at $p<0.05$.

\subsection{Content of Fatty Acids in Eggs Yolks}

The results regarding the content of FAs after 30, 60, 90, and 120 days of the experiment are presented in Table 5, Table 6, Table 7, and Table 8 respectively.

Table 5. The content of FAs in eggs (\% weight of FAs in the sample) after 30 days of the experiment.

\begin{tabular}{|c|c|c|c|c|c|c|c|}
\hline $\begin{array}{c}\text { Fatty } \\
\text { Aacids }\end{array}$ & Control & $\begin{array}{l}\text { Formulation } \\
\text { of SC-Extract }\end{array}$ & $\begin{array}{l}\text { Microalga- } \\
\text { Spirulina } \\
\text { Platensis }\end{array}$ & Residue & $\begin{array}{c}\text { Formulation } \\
\text { without } \\
\text { SC-Extract }\end{array}$ & SEM & $p$-Value \\
\hline $12: 0$ & 0.0107 & 0.0108 & 0.0107 & 0.0089 & 0.0106 & 0.00039 & 0.983 \\
\hline 14:0 & 0.273 & 0.264 & 0.271 & 0.275 & 0.259 & 0.0073 & 0.853 \\
\hline $14: 1(n-5)$ & 0.0447 & 0.0432 & 0.0447 & 0.0464 & 0.0463 & 0.00143 & 0.956 \\
\hline 15:0 & 0.0646 & 0.0633 & 0.0613 & 0.0615 & 0.0628 & 0.00181 & 0.908 \\
\hline $16: 0$ & 21.3 & 21.3 & 21.2 & 21.5 & 21.1 & 0.485 & 0.947 \\
\hline $16: 1(n-7)$ & 2.14 & 2.45 & 2.08 & 2.21 & 2.17 & 0.055 & 0.246 \\
\hline 17:0 & 0.168 & 0.162 & 0.164 & 0.161 & 0.165 & 0.0038 & 0.746 \\
\hline 18:0 & 6.70 & 6.58 & 6.85 & 6.68 & 6.61 & 0.138 & 0.542 \\
\hline $18: 1(n-9)$ & 39.4 & 40.1 & 39.3 & 40.1 & 39.5 & 0.815 & 0.747 \\
\hline $18: 2(n-6)$ & 13.3 & 13.2 & 13.4 & 12.5 & 13.1 & 0.293 & 0.709 \\
\hline $18: 3(n-6)$ & 0.0858 & 0.0878 & 0.0873 & 0.0844 & 0.0945 & 0.00222 & 0.883 \\
\hline $18: 3(n-3)$ & 0.673 & 0.663 & 0.661 & 0.645 & 0.648 & 0.0156 & 0.981 \\
\hline 19:0 & 0.0558 & 0.0576 & 0.0602 & 0.0574 & 0.0601 & 0.00143 & 0.852 \\
\hline $20: 1(n-9)$ & 0.212 & 0.223 & 0.239 & 0.217 & 0.233 & 0.0048 & 0.411 \\
\hline $20: 2(n-6)$ & 0.103 & 0.102 & 0.115 & 0.095 & 0.105 & 0.0028 & 0.198 \\
\hline $20: 3(n-3)$ & 0.098 & 0.104 & 0.105 & 0.097 & 0.096 & 0.0023 & 0.616 \\
\hline $20: 4(n-6)$ & 1.41 & 1.42 & 1.44 & 1.45 & 1.47 & 0.028 & 0.446 \\
\hline $20: 5(n-3)$ & 0.477 & 0.543 & 0.514 & 0.508 & 0.528 & 0.0142 & 0.666 \\
\hline $22: 5(n-3)$ & 0.274 & 0.296 & 0.313 & 0.309 & 0.303 & 0.0074 & 0.487 \\
\hline $22: 6(n-3)$ & 0.735 & 0.775 & 0.754 & 0.760 & 0.812 & 0.0163 & 0.655 \\
\hline SFA & 28.5 & 28.4 & 28.6 & 28.8 & 28.3 & 0.630 & 0.999 \\
\hline MUFA & 41.9 & 42.6 & 41.7 & 42.5 & 41.9 & 0.868 & 0.753 \\
\hline PUFA & 17.1 & 17.2 & 17.4 & 16.3 & 17.2 & 0.367 & 0.681 \\
\hline PUFA n-3 & 2.27 & 2.41 & 2.37 & 2.34 & 2.41 & 0.044 & 0.693 \\
\hline PUFA n-6 & 14.9 & 14.8 & 15.1 & 14.0 & 14.8 & 0.324 & 0.666 \\
\hline$n-6 / n-3$ & 6.52 & 6.14 & 6.36 & 5.98 & 6.15 & 0.065 & 0.084 \\
\hline PUFA/SFA & 0.608 & 0.607 & 0.613 & 0.571 & 0.611 & 0.0058 & 0.118 \\
\hline
\end{tabular}


Table 6. The content of FAs in the eggs (\% weight of FAs in the sample) after 60 days of the experiment.

\begin{tabular}{|c|c|c|c|c|c|c|c|}
\hline $\begin{array}{l}\text { Fatty } \\
\text { Acids }\end{array}$ & Control & $\begin{array}{l}\text { Formulation } \\
\text { of SC-Extract }\end{array}$ & $\begin{array}{c}\text { Microalga- } \\
\text { Spirulina Platensis }\end{array}$ & Residue & $\begin{array}{l}\text { Formulation } \\
\text { without SC-Extract }\end{array}$ & SEM & $p$-Value \\
\hline $12: 0$ & 0.0107 & 0.0107 & 0.0107 & 0.0089 & 0.0107 & 0.00040 & 0.854 \\
\hline $14: 0$ & 0.285 & 0.256 & 0.267 & 0.280 & 0.276 & 0.0075 & 0.584 \\
\hline $14: 1(n-5)$ & 0.0481 & 0.0398 & 0.0431 & 0.0479 & 0.0481 & 0.00151 & 0.270 \\
\hline 15:0 & 0.0550 & 0.0582 & 0.0584 & 0.0564 & 0.0534 & 0.00160 & 0.848 \\
\hline $16: 0$ & 21.5 & 21.3 & 21.2 & 21.6 & 21.9 & 0.485 & 0.872 \\
\hline $16: 1(n-7)$ & 2.25 & 2.05 & 2.07 & 2.34 & 2.28 & 0.056 & 0.255 \\
\hline 17:0 & 0.155 & 0.164 & 0.163 & 0.153 & 0.152 & 0.0036 & 0.608 \\
\hline 18:0 & 6.97 & 6.85 & 6.77 & 6.55 & 6.88 & 0.140 & 0.316 \\
\hline $18: 1(n-9)$ & 40.1 & 40.2 & 40.3 & 40.0 & 39.5 & 0.810 & 0.891 \\
\hline $18: 2(n-6)$ & 12.3 & 12.8 & 13.0 & 12.4 & 12.5 & 0.270 & 0.633 \\
\hline $18: 3(n-6)$ & 0.0799 & 0.0949 & 0.0846 & 0.0930 & 0.0950 & 0.00245 & 0.181 \\
\hline $18: 3(n-3)$ & 0.576 & 0.584 & 0.663 & 0.632 & 0.622 & 0.0144 & 0.261 \\
\hline 19:0 & 0.0603 & 0.0633 & 0.0574 & 0.0527 & 0.0544 & 0.00148 & 0.268 \\
\hline $20: 1(n-9)$ & 0.216 & 0.228 & 0.236 & 0.217 & 0.232 & 0.0046 & 0.424 \\
\hline $20: 2(n-6)$ & 0.091 & 0.098 & 0.105 & 0.218 & 0.097 & 0.0149 & 0.689 \\
\hline $20: 3(n-3)$ & 0.098 & 0.112 & 0.105 & 0.099 & 0.098 & 0.0023 & 0.219 \\
\hline $20: 4(n-6)$ & 1.47 & 1.45 & 1.41 & 1.35 & 1.41 & 0.028 & 0.493 \\
\hline $20: 5(n-3)$ & 0.517 & 0.548 & 0.461 & 0.505 & 0.538 & 0.0140 & 0.317 \\
\hline $22: 5(n-3)$ & $0.299^{a}$ & $0.339^{b}$ & $0.248^{\mathrm{Aa}}$ & $0.315^{\mathrm{AaBb}}$ & $0.379^{\mathrm{Bb}}$ & 0.0088 & 0.005 \\
\hline $22: 6(n-3)$ & 0.784 & 0.799 & 0.767 & 0.778 & 0.722 & 0.0160 & 0.625 \\
\hline SFA & 29.1 & 28.7 & 28.5 & 28.8 & 29.3 & 0.630 & 0.783 \\
\hline MUFA & 42.6 & 42.5 & 42.6 & 42.6 & 42.1 & 0.861 & 0.915 \\
\hline PUFA & 16.2 & 16.7 & 16.9 & 16.4 & 16.5 & 0.343 & 0.807 \\
\hline PUFA n-3 & 2.35 & 2.47 & 2.36 & 2.42 & 2.45 & 0.048 & 0.776 \\
\hline PUFA n-6 & 13.9 & 14.3 & 14.6 & 14.1 & 14.1 & 0.301 & 0.748 \\
\hline$n-6 / n-3$ & 5.91 & 5.82 & 6.17 & 5.84 & 5.75 & 0.051 & 0.086 \\
\hline PUFA/SFA & 0.560 & 0.586 & 0.695 & 0.575 & 0.566 & 0.0047 & 0.118 \\
\hline
\end{tabular}

SEM—standard error of measurements; SFA—saturated fatty acids; MUFA—monounsaturated fatty acids; a, b — statistically significant differences between the groups for individual parameters, at $p<0.05$.; ${ }^{\mathrm{A}}$, B — statistically significant differences between the groups for individual parameters, at $p<0.01$.

Table 7. The content of FAs in the eggs (\% weight of FAs in the sample) after 90 days of the experiment.

\begin{tabular}{|c|c|c|c|c|c|c|c|}
\hline $\begin{array}{l}\text { Fatty } \\
\text { Acids }\end{array}$ & Control & $\begin{array}{l}\text { Formulation } \\
\text { of SC-Extract }\end{array}$ & $\begin{array}{c}\text { Microalga- } \\
\text { Spirulina Platensis }\end{array}$ & Residue & $\begin{array}{c}\text { Formulation } \\
\text { without SC-Extract }\end{array}$ & SEM & $p$-Value \\
\hline $12: 0$ & 0.0178 & 0.0161 & 0.0213 & 0.0213 & 0.0196 & 0.00089 & 0.612 \\
\hline 14:0 & 0.328 & 0.304 & 0.329 & 0.341 & 0.312 & 0.0100 & 0.796 \\
\hline $14: 1(n-5)$ & $0.0430^{\mathrm{AB}}$ & $0.0449^{\mathrm{AB}}$ & $0.0479 \mathrm{AB}$ & $0.0547^{\mathrm{A}}$ & $0.0365^{\mathrm{B}}$ & 0.00164 & 0.009 \\
\hline 15:0 & 0.0579 & 0.0548 & 0.0564 & 0.0566 & 0.0582 & 0.00157 & 0.745 \\
\hline 16:0 & 22.0 & 21.8 & 22.3 & 22.7 & 21.9 & 0.506 & 0.616 \\
\hline $16: 1(n-7)$ & 2.28 & 2.19 & 2.21 & 2.36 & 2.04 & 0.057 & 0.329 \\
\hline $17: 0$ & 0.164 & 0.160 & 0.168 & 0.162 & 0.172 & 0.0040 & 0.718 \\
\hline 18:0 & 6.77 & 6.97 & 7.04 & 7.03 & 6.97 & 0.143 & 0.445 \\
\hline $18: 1(n-9)$ & 38.5 & 38.7 & 36.7 & 36.6 & 38.6 & 0.782 & 0.840 \\
\hline $18: 2(n-6)$ & 13.5 & 13.6 & 15.2 & 15.0 & 13.9 & 0.320 & 0.058 \\
\hline $18: 3(n-6)$ & 0.094 & 0.096 & 0.095 & 0.111 & 0.099 & 0.0027 & 0.304 \\
\hline $18: 3(n-3)$ & $0.515^{\mathrm{A}}$ & $0.495^{\mathrm{A}}$ & $0.311^{\mathrm{B}}$ & $0.306^{\mathrm{B}}$ & $0.532^{\mathrm{A}}$ & 0.0146 & 0.001 \\
\hline 19:0 & $0.0411^{\mathrm{a}}$ & $0.0472^{a b}$ & $0.0512^{a b}$ & $0.0544^{\mathrm{b}}$ & $0.0456^{\mathrm{ab}}$ & 0.00147 & 0.041 \\
\hline $20: 1(n-9)$ & 0.192 & 0.214 & 0.200 & 0.185 & 0.204 & 0.0044 & 0.269 \\
\hline $20: 2(n-6)$ & $0.092^{\mathrm{A}}$ & $0.097 \mathrm{~A}$ & $0.126^{\mathrm{Ba}}$ & $0.118^{\mathrm{ABab}}$ & $0.100^{b}$ & 0.0032 & 0.001 \\
\hline $20: 3(n-3)$ & 0.0996 & 0.104 & 0.106 & 0.107 & 0.101 & 0.0024 & 0.850 \\
\hline $20: 4(n-6)$ & 1.44 & 1.43 & 1.52 & 1.53 & 1.47 & 0.030 & 0.421 \\
\hline $20: 5(n-3)$ & 0.328 & $0.412^{\mathrm{a}}$ & 0.366 & 0.349 & $0.271^{b}$ & 0.0150 & 0.034 \\
\hline $22: 5(n-3)$ & 0.301 & $0.339^{a}$ & $0.272^{\mathrm{b}}$ & 0.285 & 0.288 & 0.0073 & 0.042 \\
\hline $22: 6(n-3)$ & $0.646^{\mathrm{A}}$ & $0.629^{A}$ & $0.415^{\mathrm{B}}$ & $0.440^{\mathrm{B}}$ & $0.669^{\mathrm{A}}$ & 0.0168 & 0.001 \\
\hline SFA & 29.3 & 29.4 & 30.1 & 30.4 & 29.5 & 0.658 & 0.459 \\
\hline MUFA & 41.1 & 41.2 & 39.2 & 39.2 & 40.9 & 0.835 & 0.892 \\
\hline PUFA & 17.1 & 17.2 & 18.4 & 18.2 & 17.4 & 0.380 & 0.313 \\
\hline PUFA n-3 & $1.89^{\mathrm{A}}$ & $1.98^{\mathrm{A}}$ & $1.47^{\mathrm{Ba}}$ & $1.49 \mathrm{Ba}$ & $1.86^{\mathrm{b}}$ & 0.044 & 0.001 \\
\hline PUFA n-6 & $15.2^{\mathrm{a}}$ & $15.2^{\mathrm{a}}$ & $16.9^{b}$ & $16.7^{\mathrm{ab}}$ & $15.6^{\mathrm{ab}}$ & 0.352 & 0.046 \\
\hline$n-6 / n-3$ & $8.08^{\mathrm{A}}$ & $7.70^{\mathrm{A}}$ & $11.59^{\mathrm{B}}$ & $11.3^{\mathrm{B}}$ & $8.44^{\mathrm{A}}$ & 0.204 & 0.001 \\
\hline PUFA/SFA & 0.585 & 0.586 & 0.617 & 0.603 & 0.595 & 0.0054 & 0.335 \\
\hline
\end{tabular}

SEM-standard error of measurements; SFA-saturated fatty acids; MUFA-monounsaturated fatty acids; a, b_statistically significant differences between the groups for individual parameters, at $p<0.05$.; A, B — statistically significant differences between the groups for individual parameters, at $p<0.01$. 
Table 8. The content of FAs in the eggs (\% weight of FAs in the sample) after 120 days of the experiment.

\begin{tabular}{|c|c|c|c|c|c|c|c|}
\hline $\begin{array}{l}\text { Fatty } \\
\text { Acids }\end{array}$ & Control & $\begin{array}{l}\text { Formulation } \\
\text { of SC-Extract }\end{array}$ & $\begin{array}{c}\text { Microalga- } \\
\text { Spirulina Platensis }\end{array}$ & Residue & $\begin{array}{c}\text { Formulation } \\
\text { without SC-Extract }\end{array}$ & SEM & $p$-Value \\
\hline $12: 0$ & $0.00538^{\mathrm{A}}$ & $0.00895 \mathrm{ABab}$ & $0.00536^{a}$ & $0.00534^{a}$ & $0.0106^{\mathrm{Bb}}$ & 0.00060 & 0.005 \\
\hline $14: 1(n-5)$ & 0.047 & 0.046 & 0.046 & 0.577 & 0.560 & 0.0018 & 0.216 \\
\hline 15:0 & $0.0630^{\mathrm{a}}$ & $0.0615^{a b}$ & $0.0500^{\mathrm{b}}$ & $0.0563^{a b}$ & $0.0515^{a b}$ & 0.00170 & 0.049 \\
\hline $16: 0$ & 22.1 & 21.7 & 22.0 & 22.2 & 21.9 & 0.492 & 0.886 \\
\hline 18:0 & 6.91 & 7.24 & 7.41 & 6.75 & 6.87 & 0.146 & 0.091 \\
\hline $18: 1(n-9)$ & 38.1 & 37.8 & 38.3 & 38.7 & 38.4 & 0.776 & 0.695 \\
\hline $18: 2(n-6)$ & 14.4 & 14.9 & 13.5 & 12.9 & 13.7 & 0.323 & 0.229 \\
\hline $18: 3(n-6)$ & 0.0917 & 0.101 & 0.0902 & 0.0943 & 0.0973 & 0.00225 & 0.671 \\
\hline $18: 3(n-3)$ & 0.420 & 0.419 & 0.370 & 0.428 & 0.404 & 0.0102 & 0.238 \\
\hline $20: 4(n-6)$ & 1.49 & 1.54 & 1.53 & 1.50 & 1.47 & 0.030 & 0.906 \\
\hline $20: 5(n-3)$ & 0.537 & 0.581 & 0.606 & 0.517 & 0.549 & 0.0137 & 0.247 \\
\hline $22: 5(n-3)$ & $0.274^{\mathrm{a}}$ & $0.304^{\mathrm{ab}}$ & $0.333^{b}$ & $0.269^{\mathrm{a}}$ & $0.308^{a b}$ & 0.0075 & 0.039 \\
\hline $22: 6(n-3)$ & 0.547 & 0.568 & 0.468 & 0.509 & 0.510 & 0.0114 & 0.055 \\
\hline SFA & 29.6 & 29.5 & 30.0 & 29.6 & 29.3 & 0.642 & 0.884 \\
\hline MUFA & 40.5 & 40.1 & 40.7 & 41.1 & 41.0 & 0.830 & 0.629 \\
\hline PUFA & 18.0 & 18.7 & 17.2 & 16.5 & 17.3 & 0.387 & 0.235 \\
\hline PUFA n-3 & 1.88 & 1.99 & 1.89 & 1.83 & 1.87 & 0.038 & 0.628 \\
\hline PUFA n-6 & 16.1 & 16.7 & 15.3 & 14.6 & 15.4 & 0.353 & 0.250 \\
\hline$n-6 / n-3$ & 8.61 & 8.39 & 8.12 & 8.06 & 8.23 & 0.101 & 0.195 \\
\hline PUFA/SFA & $0.612^{\mathrm{AB}}$ & $0.637^{\mathrm{A}}$ & $0.577^{\mathrm{AB}}$ & $0.561^{\text {В }}$ & $0.591 \mathrm{AB}$ & 0.0067 & 0.008 \\
\hline
\end{tabular}

Analysis of the results did not show a significant effect of the used additives on the FA profile after 30 days of the experiment.

After 60 days of the experiment, the eggs of hens from the groups receiving the formulation of SC-extract and formulation without SC-extract were characterized by a significantly higher content of DPA compared to hens from the control group and group receiving the addition of microalgae.

After 90 days of the experiment, the eggs of hens from the group receiving residue were characterized by a significantly higher $(p<0.01)$ content of 14:1 (n-5) compared to the group receiving formulation without SC-extract. Eggs of hens from the group receiving the residue and the addition of microalgae were characterized by a significantly $(p<0.01)$ lower content of ALA compared to other groups. Eggs from the control group were characterized by a significantly $(p<0.01)$ lower content of 19:0 compared to group receiving the residue. In the eggs of hens from the control group and those receiving the formulation of SC-extract, a significantly lower $(p<0.01) \mathrm{C} 20: 2(\mathrm{n}-6)$ content was noted compared to the group receiving the addition of microalgae. Eggs of hens from the group receiving the addition of microalgae were also characterized by a significantly higher $(p<0.05)$ content of 20:3 (n-3) compared to the group receiving formulation without SC-extract. Eggs of hens from the control group and these receiving formulation of SC-extract and formulation without SC-extract were characterized by a significantly higher $(p<0.01)$ content of DHA compared to the groups receiving the addition of microalgae and residue. Eggs of hens from the control group and those receiving formulation of SC-extract were also characterized by a significantly higher $(p<0.01)$ content of PUFA n-3 compared to the groups receiving the addition of microalgae and residue. Microalgae and residue groups were also characterized by a significantly lower $(p<0.05)$ content of PUFA n-3 compared to group receiving formulation without SC-extract. In eggs from the group receiving the microalgae, a significantly higher $(p<0.05)$ content of PUFA $n-6$ was found compared to the control group and group receiving formulation of SC-extract. The ratio of n-6/n-3 acids was significantly lower $(p<0.01)$ in the eggs of 
hens from the control group, formulation of SC-extract group, and formulation without SC-extract group compared to the groups receiving microalgae and residue.

After 120 days of the experiment, it was shown that eggs from group receiving the formulation without SC-extract had significantly less $(p<0.01) 12: 0$ than in eggs from the control group. Eggs from the group receiving formulation without SC-extract were also characterized by a significantly lower $(p<0.05)$ content of 12:0 compared to the microalgae and residue groups. Eggs from the control group were characterized by a significantly higher $(p<0.05)$ content of 15:0 compared to the group receiving the addition of microalgae. Eggs from the control and residue groups were characterized by a significantly lower $(p<0.05)$ content of DPA than microalgae group. Control eggs showed a significantly higher PUFA/SFA ratio $(p<0.01)$ than eggs from the residue group.

It is difficult to compare the obtained results with the literature data, because the effect of algal extracts added to the drinking water has not been studied so far. More data concern the effect of algae on the content of FAs in eggs, for example $[4,8,9,12,13]$. Šefer et al. [12] found that the inclusion of algal product DHA Gold ${ }^{\circledR}$ from Schizochytrium spp. (at the optimal dose $10 \mathrm{~g} \mathrm{~kg}^{-1}$ of feed among 5 and $7 \mathrm{~g} \mathrm{~kg}^{-1}$ of feed) led to significant increases of DHA, but not EPA, content in eggs. Bruneel et al. [13] also found that EPA derived from microalga Nannochloropsis gaditana was hardly accumulated in yolk lipids. It preferentially converted to DHA and deposited in yolk phospholipids. For the algal dose of $10 \%$, the level of DHA in egg yolk was doubled when compared to the eggs from the control group fed with a standard feed.

The results obtained in the present study show that the algal extract is a better source of FAs than the raw biomass of microalgae. However, this solution is much more expensive due to the costs of SFE. Because of this fact, Colla et al. [21] suggested direct consumption of Spirulina as a nutritional supplement instead of extract. On the other hand, the addition of the microalgal SC-extract to the diet is very relatively low (in this study $1.3 \%$ ) and assures better enrichment of eggs with FAs. Some authors indicate that higher content of algae in the diet did not increase the content of some FA. For example, Al-Harthi and El-Deek [9] examined the effect of different contents $(0 \%, 3 \%$, and $6 \%)$ of brown marine algae (Sargassum dentifebium) on yolk lipid profiles in egg yolks. It was shown that higher contents of algal biomass in the diet caused a decrease in the content of FAs in eggs. A significant increase in 18:1 (n-9) content was observed when feed containing 3\% of algae was supplied to the hens' diet, while the content of this FA decreased with an increasing dose of algae. Moreover, the inclusion of either $3 \%$ or $6 \%$ of algae resulted in a significant decrease of the content of 18:2 (n-6).

During the feeding experiment, the $n-3 / n-6$ ratio was also changed. The appropriate ratio of n-6/n-3 acids should be 4-5/1 [38]. After day 30 of the experiment, the best ratio of n-3/n-6 (5.98/1) was characterized by the group fed with the formulation containing residue. The control group had the worst acid ratio (6.52/1). However, these differences were not statistically significant. After 60 days of experiment, the best ratio of FA was characterized by the group fed with the formulation without SC-extract (5.75/1). The worst was the group receiving the addition of microalgae (6.17/1), however these differences also were not statistically significant. After 90 days of experiment, the group fed with the formulation of SC-extract was characterized by the best ratio of FAs (7.70/1). The group receiving the microalgal supplement had the worst FA ratio (11.59/1) and it was statistically significant difference $(p<0.01)$. After 120 days of experiment, the best ratio of these acids was characterized by the group fed with the formulation containing residue (8.06/1) while the worst was for the control group (8.61/1) - not statistically significant. In the course of the whole experiment, the best ratio of FA was recorded after 60 days, in a group fed with formulation without SC-extract (5.75/1) and the worst after 90 days of, in microalgae fed group (11.59/1). Generally, the worst FAs ratio was recorded in egg yolks collected after 90 days of the experiment. The results suggest that the consumption of eggs fortified with PUFAs may discourage their daily intake to the recommended standards. A similar ratio of n-6/n-3 (6.5-7.7/1) acids was obtained by Farrel [39] who supplemented hens' diet with fish oil and a combination of fish and vegetable oils. 


\section{Conclusions}

In the present study, new dietary feed supplement for laying hens, with the potential to increase the concentration of PUFAs in eggs was investigated. The obtained results suggest that supplementation of the diet with examined additives has no effect on the performance of laying hens. It can also be stated that the greatest influence on the FA profile in the egg was noted for the SC-extract. However, this profile was similar in the group receiving the addition of emulsifier. Thus, it is difficult to draw definite conclusions. Accordingly, further research should be continued in this direction.

Author Contributions: Conceptualization, I.M., M.K., S.O., B.Ł., E.R. and K.C.; methodology, I.M., M.K., S.O., B.Ł., R.W., E.R. and K.C.; software, D.K.; validation, M.K., K.C. and E.R.; formal analysis, I.M., S.O. and K.C.; investigation, M.A., D.K. and R.W.; data curation, I.M., M.A., R.W. and B.E.; writing-original draft preparation, I.M., M.A. and D.K., writing-review and editing, M.K., S.O. and K.C.; visualization, I.M. and D.K.; supervision, K.C.; project administration, I.M., M.K., S.O., B.Ł., E.R. and K.C., funding acquisition, I.M., M.K., S.O., B.Ł., E.R. and K.C. All authors have read and agreed to the published version of the manuscript.

Funding: This project is financed in the framework of grant entitled: Innovative technology of seaweed extracts - components of fertilizers, feed and cosmetics (PBS/1/A1/2/2012) attributed by The National Centre for Research and Development in Poland.

Conflicts of Interest: The authors declare no conflict of interest.

\section{References}

1. Gul, K.; Singh, A.K.; Jabeen, R. Nutraceuticals and functional foods: The foods for the future world. Crit. Rev. Food Sci. Nutr. 2016, 56, 2617-2627. [CrossRef] [PubMed]

2. Zarate, R.; El Jaber-Vazdekis, N.; Tejera, N.; Perez, J.A.; Rodriguez, C. Significance of long chain polyunsaturated fatty acids in human health. Clin. Transl. Med. 2017, 6, 25. [CrossRef] [PubMed]

3. Simopoulos, A.P. Human requirement for n-3 polyunsaturated fatty acids. Poult. Sci. 2000, 79, 961-970. [CrossRef]

4. Carrillo, S.; Ríos, V.H.; Calvo, C.; Carranco, M.E.; Casas, M.; Pérez-Gil, F. n-3 fatty acid content in eggs laid by hens fed with marine algae and sardine oil and stored at different times and temperatures. J. Appl. Phycol. 2012, 24, 593-599. [CrossRef]

5. Herber, S.M.; van Elswyk, M.E. Dietary marine algae promotes efficient deposition of n-3 fatty acids for the production of enriched shell eggs. Poult. Sci. 1996, 75, 1501-1507. [CrossRef] [PubMed]

6. Fredriksson, S.; Elwinger, K.; Pickova, J. Fatty acid and carotenoid composition of egg yolk as an effect of microalgae addition to feed formula for laying hens. Food Chem. 2006, 99, 530-537. [CrossRef]

7. Rizzi, L.; Bochicchio, D.; Bargellini, A.; Parazza, P.; Simioli, M. Effects of dietary microalgae, other lipid sources, inorganic selenium and iodine on yolk n-3 fatty acid composition, selenium content and quality of eggs in laying hens. J. Sci. Food Agricult. 2009, 89, 1775-1781. [CrossRef]

8. Gładkowski, W.; Kiełbowicz, G.; Chojnacka, A.; Bobak, Ł.; Spychaj, R.; Dobrzański, Z.; Trziszka, T.; Wawrzeńczyk, C. The effect of feed supplementation with dietary sources of n-3 polyunsaturated fatty acids, flaxseed and algae Schizochytrium sp., on their incorporation into lipid fractions of Japanese quail eggs. Int. J. Food. Sci. Technol. 2014, 49, 1876-1885. [CrossRef]

9. Al-Harthi, M.A.; El-Deek, A.A. Effect of different dietary concentrations of brown marine algae (Sargassum dentifebium) prepared by different methods on plasma and yolk lipid profiles, yolk total carotene and lutein plus zeaxanthin of laying hens. Ital. J. Anim. Sci. 2012, 11, 347-353. [CrossRef]

10. Grigorova, S.; Surdjiiska, S.; Banskalieva, V.; Dimitrov, G. The effect of biomass from green algae of Chlorella genus on the biochemical characteristics of table eggs. J. Cent. Eur. Agricult. 2006, 7, 111-116.

11. Lemahieu, C.; Bruneel, C.; Termote-Verhalle, R.; Muylaert, K.; Buyse, J.; Foubert, I. Impact of feed supplementation with different omega-3 rich microalgae species on enrichment of eggs of laying hens. Food Chem. 2013, 141, 4051-4059. [CrossRef] [PubMed]

12. Šefer, D.; Andonov, A.; Šobajić, S.; Marković, R.; Radulović, S.; Jakić-Dimić, D.; Petrujkić, B. Effects of feeding laying hens diets supplemented with omega 3 fatty acids on the egg fatty acid profile. Biotechnol. Animal. Husb. 2011, 27, 679-686. [CrossRef] 
13. Bruneel, C.; Lemahieu, C.; Fraeye, I.; Ryckebosch, E.; Muylaert, K.; Buyse, J.; Foubert, I. Impact of microalgal feed supplementation on omega-3 fatty acid enrichment of hen eggs. J. Funct. Foods. 2013, 5, 897-904. [CrossRef]

14. Saeid, A.; Chojnacka, K.; Opaliński, S.; Korczyński, M. Biomass of Spirulina maxima enriched by biosorption process as a new feed supplement for laying hens. Algal Res. 2016, 19, 342-347. [CrossRef]

15. Van Elswyk, M.E. Comparison of n-3 fatty acids sources in laying hen rations for improvement of whole egg nutritional quality: A review. Br. J. Nutr. 1997, 78, 61-69. [CrossRef]

16. Michalak, I.; Chojnacka, K. Algae as production systems of bioactive compounds. Eng. Life Sci. 2015, 15, 160-176. [CrossRef]

17. Koru, E. Earth Food Spirulina (Arthrospira): Production and Quality Standards, Food Additive; El-Samragy, Y., Ed.; InTech: London, UK, 2012; ISBN 978-953-51-0067-6. Available online: http://www.intechopen.com/books/ food-additive/earth-food-spirulina-arthrospira-production-and-qualitystandarts/ (accessed on 15 June 2016).

18. Chaiklahan, R.; Chirasuwan, N.; Loha, V.; Bunnag, B. Lipid and fatty acids extraction from the cyanobacterium Spirulina. Sci. Asia 2008, 34, 299-305. [CrossRef]

19. Zinnai, A.; Venturi, F.; Sanmartin, C.; Andrich, G. A simplified method to estimate the time evolution of oil extraction from different substrates by supercritical $\mathrm{CO}_{2}$. Am. J. Analyt. Chem. 2012, 3, 939-945. [CrossRef]

20. Mühling, M.; Belay, A.; Whitton, B.A. Variation in fatty acid composition of Arthrospira (Spirulina) strains. J. Appl. Phycol. 2005, 17, 137-146. [CrossRef]

21. Colla, L.M.; Bertolin, T.E.; Costa, J.A.V. Fatty acids profile of Spirulina platensis grown under different temperatures and nitrogen concentrations. Zeitschrift Für Naturforschung C 2004, 59, 55-59. [CrossRef]

22. Mendes, R.L.; Reis, A.D.; Palavra, A.F. Supercritical $\mathrm{CO}_{2}$ extraction of $\gamma$-linolenic acid and other lipids from Arthrospira (Spirulina) maxima: Comparison with organic solvent extraction. Food Chem. 2006, 99, 57-63. [CrossRef]

23. Quihui, H. Supercritical carbon dioxide extraction of Spirulina platensis component and removing the stench. J. Agricult. Food. Chem. 1999, 47, 2705-2706. [CrossRef] [PubMed]

24. Andrich, G.; Zinnai, A.; Nesti, U.; Venturi, F. Supercritical fluid extraction of oil from microalga Spirulina (Arthrospira) platensis. Acta Aliment. 2006, 35, 195-203. [CrossRef]

25. Rój, E. Plant material extraction using supercritical $\mathrm{CO}_{2}$. In Supercritical $\mathrm{CO}_{2}$ Extraction and Its Applications; Rój, E., Ed.; Polish Foundation of the Opportunities Industrialization Centers "OIC Poland": Lublin, Poland, 2014; pp. 7-21. ISBN 978-83-86499-96-0.

26. Michalak, I.; Górka, B.; Wieczorek, P.P.; Rój, E.; Lipok, J.; Łęska, B.; Messyasz, B.; Wilk, R.; Schroeder, G.; Dobrzyńska-Inger, A.; et al. Supercritical fluid extraction of algae enhances levels of biologically active compounds promoting plant growth. Eur. J. Phycol. 2016, 51, 243-252. [CrossRef]

27. Smulikowska, S. Normy Żywienia Drobiu (Nutrient Requirements of Poultry), Wyd; IFiZZ Warsaw: Warsaw, Poland, 2008.

28. Świniarska, M.; Korczyński, M.; Opaliński, S.; Dobrzański, Z.; Baron, A.; Chrzanowska, M.; Bobak, Ł. The algae biomass in animal production. In Innovative Bio-Products for Agriculture: Algal Extracts in Products for Human, Animals and Plants; Chojnacka, K., Michalak, I., Eds.; Nova Science Publishers, Inc.: Hauppauge, NY, USA, 2016.

29. Sahena, F.; Zaidul, I.S.M.; Jinap, S.; Karim, A.A.; Abbasa, K.A.; Norulaini, N.A.N.; Omar, A.K.M. Application of supercritical $\mathrm{CO}_{2}$ in lipid extraction-A review. J. Food. Eng. 2009, 95, 240-253. [CrossRef]

30. Halim, R.; Danquah, M.K.; Webley, P.A. Extraction of oil from microalgae for biodiesel production: A review. Biotechnol. Adv. 2012, 30, 709-732. [CrossRef]

31. Messyasz, B.; Łęska, B.; Fabrowska, J.; Pikosz, M.; Rój, E.; Cieślak, A.; Schroeder, G. Biomass as freshwater Cladophora as agriculture and the cosmetic industry. Open Chem. 2015, 13, 1108-1118. [CrossRef]

32. Ibañez, E.; Herrero, M.; Mendiola, J.A.; Castro-Puyana, M. Extraction and characterization of bioactive compounds with health benefits from marine resources: Macro and micro algae, cyanobacteria, and invertebrates. In Marine Bioactive Compounds: Sources, Characterization and Applications; Hayes, M., Ed.; Springer: New York, NY, USA, 2012.

33. Batista, A.P.; Gouveia, L.; Bandarra, N.M.; Franco, J.M.; Raymundo, A. Comparison of microalgal biomass profiles as novel functional ingredient for food products. Algal Res. 2013, 2, 164-173. [CrossRef] 
34. Fabrowska, J. Methods of Isolation and Analysis of Bioactive Compounds from Selected Freshwater Green Algae Species. Ph.D. Thesis, Adam Mickiewicz University in Poznan, Poznan, Poland, 17 July 2017. Available online: http://hdl.handle.net/10593/18627 (accessed on 12 January 2018).

35. Mariey, Y.A.; Samak, H.R.; Ibrahem, M.A. Effect of using Spirulina platensis algae as a feed additive for poultry diets: 1-productive and reproductive performances of local laying hens. Poult. Sci. 2012, 32, 201-215.

36. Zahroojian, N.; Moravej, H.; Shivazad, M. Comparison of marine algae (Spirulina platensis) and synthetic pigment in enhancing egg yolk colour of laying hens. Br. Poultry. Sci. 2011, 52, 584-588. [CrossRef]

37. Zahroojian, N.; Moravej, H.; Shivazad, M. Effects of dietary marine algae (Spirulina platensis) on egg quality and performance of laying hens. J. Agricult. Sci. Technol. 2013, 15, 1353-1360.

38. Materac, E.; Marczyński, Z.; Bodek, K.H. The role of long-chain fatty acids omega-3 and omega-6 in human body. Bromat. Chemia Toksykol. 2013, 2, 225-233.

39. Farrel, D.J. Enrichment of hen eggs with n-3 long-chain fatty acids and evaluation of enriched eggs in humans. Am. J. Clin. Nutr. 1998, 68, 538-544. [CrossRef] [PubMed]

(C) 2020 by the authors. Licensee MDPI, Basel, Switzerland. This article is an open access article distributed under the terms and conditions of the Creative Commons Attribution (CC BY) license (http://creativecommons.org/licenses/by/4.0/). 